\title{
La sociedad manchega en vísperas del Descubrimiento
}

\author{
Paulina López Pita *
}

El año 1992 ha sido prolijo en conmemorar una serie de acontecimientos que tuvieron lugar hace 500 años. Pero el hecho de que se conmemoren, creo, no debe entenderse en el sentido de aprobación como sucesos dignos de encomio. Esa fecha y los actos celebrados por tal motivo han servido como recuerdo continuando así la trayectoria seguida estos últimos años de traer a la memoria o celebrar los centenarios y milenarios de sucesos históricos que tuvieron una honda repercusión en el devenir de la Historia ${ }^{1}$.

Antes de adentrarnos en el tema que nos ocupa: La sociedad manchega en vísperas del Descubrimiento, debemos hacer algunas precisiones en lo tocante al área geográfica y al espacio cronológico al que voy a referirme. Respecto al primero de ellos ¿Cuál es el territorio al que se alude cuando hablamos de la Mancha como espacio geográfico? Hay que tener presente que aunque actualmente en las divisiones por Comunidades Autónomas se engloban bajo la denominación de Castilla-La Mancha cinco provincias: Guadalajara, Cuenca, Ciudad Real, Albacete y Toledo, voy a centrarme en un ámbito territorial muy concreto que pertenecía en la Edad Media al Reino de Toledo, junto con la Alcarria, el valle medio del Tajo y la serranía de Cuenca. Éste en su conjunto presenta unas características propias y constituye una entidad histórica conocida por LaMancha $^{2}$. Denominación que encontramos documentada por primera vez

UNED. Madrid.

El IV Centenario del Descubrimiento de América fue conmemorado en la ciudad de Toledo. Cfr. Fernández González, F., Toledo en el IV Centenario del Descubrimiento de América. Toledo 1991. Y SALRACH, J. M., «El Millenari com a pretext per a un debat entre historiadors», Debat. Valencia 1988, págs. 42-59.

2 Cfr. Izouierdo, R., «Aproximación a las fuentes para el estudio de Castilla La Mancha en la Edad Media", Actas del 1. ${ }^{\text {er }}$ Congreso de $H^{a}{ }^{a}$ de Castilla-La Mancha. Ciudad Real 1988, T. I, pág. 41. 
en el siglo XIV ${ }^{3}$, y cuyos límites son difíciles de fijar con exactitud, ya que este punto ha sido objeto de discusión por parte de algunos estudiosos de este área, y de una manera muy especial en lo referente a los zonas limítrofes del sur de la actual provincia de Toledo ${ }^{4}$.

No obstante y teniendo presente que los límites de La Mancha no son exactos y que como afirmaba el citado Rafael Fernández Pombo «querer poner límites a La Mancha es algo así como poner puertas al campo» 5 , admitimos de modo genérico que La Mancha comprende parte de la provincia de Toledo, el sur, parte de la provincia de Cuenca, suroeste, que junto con Alcázar de San Juan, los paisajes cervantinos de El Toboso y el Campo de Criptana, formarían la denominada Mancha Alta; la mayor parte de la provincia de Ciudad Real, que abarcaría la llamada Mancha Baja; y parte de la provincia de Albacete hacia el reino de Valencia y las estribaciones de la sierra de Alcaraz $^{6}$.

Todo este espacio presenta desde el punto de vista topográfico una misma característica: su llanura, significado de la raíz árabe de donde procede el topónimo Albacete (Al-Basit) ${ }^{\text {? }}$. Y desde el punto de vista climático viene caracterizada por su sequedad y aridez, buena prueba de ello lo encontramos en la propia denominación de esta zona manchega, voz que significa tierra seca ${ }^{8}$.

$Y$ en segundo lugar y respecto al espacio cronológico en el cual vamos a centrarnos he fijado el comienzo a mediados del siglo XV cuando estalla la guerra civil en Castilla, y su límite en los inicios de la siguiente centuria. En este medio siglo, aproximadamente, tuvieron lugar acontecimientos de suma importancia desde el punto de vista político que tendrán lógicamente una repercusión muy directa en el conjunto de la sociedad de aquel momento, que constituye el objeto de nuestra atención y que va a asistir a los preámbulos de la llegada de los hispanos a América.

\footnotetext{
${ }^{3}$ Así consta en un privilegio fundacional firmado por el maestre don Fadrique en 1353. Cfr. Corchado Soriano, M. «La Mancha en el siglo xVI», Hispania, XXXIII, 1973, pág. 153.

4 Cfr. Fernández Pombo, R., Mora y La Mancha, Col. Temas Morachos, I. Madrid 1973, pág. 19 , quien mantuvo una "cordial» polémica con D. Fernando Jiménez de Gregorio en torno a si Mora era o no tierra de La Mancha.

Fernández Pombo, R., Op. cit., pág. 8.

- Cfr. Criado del Val, M., Teoría de Castilla La Nueva. Madrid 1969, págs. 30-31.

7 Cfr. Abdulla Enan, M., Toponimia Arábigo-española.Instituto Egipcio de Estudios islámicos. Madrid 1976, pág. 7.

8 Véase en este sentido Martínez Ruiz, J., "Contribución al estudio de la toponimia medieval de Castilla-La Mancha", en Actas del $1 .{ }^{e r}$ Congreso de $H .{ }^{a}$ de Castilla-La Mancha.Ciudad Real 1988, t.V. págs: 117-125. Señala para La Mancha la raíz árabe manya que significa «alta planicie».
} 


\section{ANTECEDENTES POLITICOS}

Es de todos conocido que la amplia llanura que se extiende desde el Tajo al Guadiana y desde la serranía de Cuenca hasta Sierra Morena quedó prácticamente despoblada bajo el dominio musulmán, y de un modo especial durante los últimos años del Califato. La escasa población que allí permaneció de forma residual dedicada al pastoreo no dio posibilidad de establecer un encuadramiento institucional definido ${ }^{9}$, y fue lo que condujo a Gautier-Dalché a hablar de la formación de un «glacis» entre tierras musulmanas y cristianas ${ }^{10}$

Desde 1085, fecha de la toma de Toledo, hasta 1212, triunfo cristiano en las Navas de Tolosa, La Mancha estuvo despoblada. Durante este siglo, fue tierra de nadie, en la cual se adentraban mediante continuas incursiones ejércitos cristianos y musulmanes. Por una parte, desde la ciudad de Toledo, que se convirtió después de 1085 en la avanzada de las expediciones cristianas hacia los reinos de taifas. Y por otra, Almorávides primero y Almohades después protagonizaron diversas algaras a tierras cristianas, algunas con éxito, teniendo como principal objetivo la propia ciudad de Toledo ${ }^{11}$.

A comienzos del siglo XII, 1110 aprox., el ejército almoravid conseguía su máxima expansión, extendiendo su dominio desde el Mediterráneo al Atlántico, siguiendo los cursos de los ríos Ebro y Tajo respectivamente. Pero también estos años marcaban el inicio de su carrera descendente con la pérdida de Zaragoza en 1118.

Las desavenencias surgidas en Al-Andalus fueron aprovechadas por el rey Alfonso VII, quien sacando provecho de tal situación, se apoderó de Castillo de Calatrava, desde donde saldrán expediciones de castigo hacia Levante, recuperando Uclés en 1149.

En 1195 el califa almohade plantaba su campamento en Congosto, entre Alarcos y Salvatierra, y por su parte el rey cristiano, Alfonso VIII, concentraba sus tropas en las inmediaciones del cerro de Alarcos, donde sufrió una terrible derrota. Este triunto almohade les permitió seguir hasta

9 Moxó, S. de, "La repoblación castellana del Reino de Toledo", Studia Humanistica. Madrid, UNED, 1976, vol. l, pág. 65. y Repoblación y sociedad en la España Cristiana medieval. Madrid 1979, pág. 241.

10 Gautier-Dalché, J., «Islam et chrétienté en Espagne au Xlle siècle. Contribution à l'étude de la notion de frontière», en Hesperis, 1969.

11 Nunca más pasó Toledo al poder de los musulmanes, pero éstos tuvieron éxito en Uclés, y como consecuencia de este triunfo los cristianos perdieron los castillos de Huete, Ocaña y Cuenca. 
Calatrava, plaza que tomaron por asalto, más tarde sitiaron el castillo de Salvatierra, cuyos defensores, después de dos meses de asedio, se vieron obligados a rendirse.

El hecho de que los Almohades se adueñaran de Salvatierra tuvo una profunda repercusión, ya que incitó la unión de los reyes cristianos: Pedro II de Aragón, Alfonso IX de León y Sancho VII de Navarra, quienes aunaron sus ejércitos para frenar el avance del Islam. La consecuencia fue la derrota de los Almohades en las Navas de Tolosa ${ }^{12}$.

Fue precisamente en el interior del área que esiudiamos donde tuvieron lugar los preparativos de uno de los más importantes y trascendentales encuentros entre los ejércitos cristianos y musulmanes. Las tropas cristianas después de haber acampado junto a los arroyos de Guadajaraz, Guadacelete y Algodor, continuaron hacia la fortaleza de Guadalerza, en el límite divisorio entre las actuales provincias de Toledo y Ciudad Real; llegando a Malagón poco tiempo después. Los cristianos asedian Calatrava que se vio obligada a capitular. Alfonso VII solo ya con el ejército "hispano» ${ }^{13}$, se dirigió hacia Alarcos y Salvatierra, conquistando la fortaleza de Piedrabuena y Caracuel. Desde este último lugar se dirigieron a los pasos de Sierra Morena para intentar cruzar el paso de Muradal ${ }^{14}$ y llegar a la llanura de las Navas de Tolosa. Vemos, pues, cómo La Mancha se había convertido en un campo de batalla hasta 1212 .

Así pues y lógicamente en «este campo de batalla» nos vamos a encontrar a una reducida población que habitaba y defendía fortalezas y castillos situados en lugares estratégicos que van a caracterizar, al mismo tiempo el paisaje manchego. Esta red de castillos que constituían auténticas bases militares van a incidir notablemente en la forma de asentamiento en La Mancha, ya que junto a su labor defensiva van a ser un catalizador para la ordenación repobladora ${ }^{15}$.

El rey Alfonso VII había hecho entrega a ciertos caballeros de grandes territorios con sus respectivos castillos y aldeas para hacer frente a los

12 La unión de los Reyes cristianos era delicada y frágil, por lo que Inocencio Ill dirigió una bula a los arzobispos de Toledo y Compostela ordenándoles que procuraran que no se rompiera la paz entre los reyes hispanos mientras durase la campaña contra los Almohades. Por este tiempo Simón de Monfort dirigía una cruzada contre los Albigenses.

13 La capitulación no gusto a los ultramontanos pues estaban acostumbrados al saqueo y exterminio de las ciudades albigenses poi lo que desde allí abandonaron esta empresa.

14 Véase sobre su importante localización, Rodríguez MolinA, J. «El puerto del Muradal. Permeabilidad entre Castilla-La Mancha y Andalucía", Actas del $1 .{ }^{e r}$ Congreso de $\mathrm{H}^{\text {a }}$ de CastillaLa Mancha. Ciudad Real 1988, T. V, págs. 137-144.

15 Moxó, S. de, «Derecho y Arquitectura militar en la España Cristiana Medieval», Revista Española de Derecho Militar, $n^{\circ}$ 9, 1961. 
posibles ataques de los Almohades ${ }^{16}$, pero al resultar insuficiente el trabajo de los citados caballeros, estos territorios se entregaron a las conocidas Órdenes Militares. Fundadas, en términos generales, a mediados del siglo XII, vienen a significar el papel que en otro tiempo hicieron las milicias de un tenente o de un concejo, supliendo a monasterios y a los citados concejos mediante su doble actividad, defensiva, por una parte, y como foco de atracción de población por otra. Algunos estudiosos vinculan a los miembros de estas órdenes con los monjes-guerreros habitantes del ribat musulmán, en los que se funden sus deberes militares y religiosos ${ }^{17}$.

Las Órdenes Militares encargadas de la conquista y colonización de La Mancha van a marcar el carácter fronterizo y militar de esta zona, señalando los límites entre la meseta toledana, de la cual no se aprecian desde el punto de vista geográfico grandes diferencias, y Andalucía. La comunicación entre ellas a través de La Mancha se mantuvo durante la Edad Media e incluso a lo largo del siglo XVI según refiere el Repertorio de Villuga ${ }^{18}$.

La primera Orden Militar que se constituyen es la Orden de Calatrava, fundada con monjes del Císter por el abad Raimundo de Fitero una vez que Sancho III de Castilla le hizo entrega de aquel lugar en 1164. Extendía sus dominios, a grandes rasgos, por la denominada Mancha Occidental.

En la llamada Mancha Alta se asentó la Orden de Santiago, fundada en $1170^{19}$. El rey Alfonso VIII, le hizo entrega del castillo de Mora en el año $1180^{20}$ y de Uclés, donde se instaló el Maestrazgo de la Orden en 1174, concediendo cinco años después el Fuero de Sepúlveda con al-

16 Alfonso VIl entregó Mora a Rodrigo Muñiz (1150); Consuegra a Rodrigo Rodríguez (1155) y Alcázar a Juan Muñiz. Véase GonzÁlez, J., Repoblación de Gastilla la Nueva. Madrid 1975, T. I, pág. 263.

17 Véase en este sentido Oliver Asín, J., Origen árabe de rebato, arrobda y sus homónimos. Madrid 1928. Su relación con el ribat árabe no es tan clara para otros, véase LomAX, D. W., La orden de Santiago. Madrid 1965, pág. 3.

18 La Mancha ha sido considerada como zona de paso y de ahí la abundancia de trabajos sobre los caminos transitados en este período. MENÉndez PIDAL, G., Los caminos en la $H .^{\text {a de }}$ España. Madrid 1951. CoRChado SORIANo, M., "Vías romanas del Tajo al Guadalquivir», Archivo Español de Arqueología, 1969, págs. 132-136. El camino de Toledo a Córdoba, I. de Estudios Manchegos. Pasos naturales y antiguos caminos entre Jaén y La Mancha, Estudios Jiennenses; y HeRnándeZ, F., "Los caminos de Córdoba a Toledo en época califal», Al-Andalus, XXIV, 1959, págs. 31-34. Y CRIADO DEL VAL, Op. cit., págs. 58-60.

19 Martín, J. L., Orígenes de la Orden Militar de Santiago (1170-1195). Barcelona 1974.

20 Rodriguez Garcia, H., El señorio de Mora. De la Orden de Santiago a los Rojas Toledanos. Toledo 1990, pág. 33. 
gunas modificaciones ${ }^{21}$. Desde allí se extendería hacia el sur y hacia el Campo de Montiel.

En el espacio existente entre los dominios de estas dos Órdenes se asentaba la Orden de San Juan quien gobernó desde 1162 el Campo de Criptana con Villajos, Quero y Tirez (Atarez) tierras que el rey le había entregado hasta 1237, año en el que mediante un acuerdo con la Orden de Santiago estos términos pasaron al dominio de esta última ${ }^{22}$. En 1183 recibió la Orden Consuegra en cuya fortaleza se instaló la sede prioral de la Orden en Castilla, convirtiéndose en un importante señorío manchego. A estas posesiones vinieron a sumarse los castillos de Peñarroya, Villacentenos y La Ruidera, con el objetivo de frenar los posibles ataques que vinieran de Montiel. A la población que se asentó en torno al castillo de Consuegra se le dio el Fuero de Cuenca.

Estas Órdenes Militares trataron de atraer a gentes para que viniesen a poblar este territorio tan escasamente habitado a pesar de las concesiones hechas en sus Fueros y Cartas de población ${ }^{23}$ con tal fin y del apoyo prestado por los monarcas, llegando a fundar villas y concejos como fue el caso de Alarcón en la zona oriental y de Alarcos en el oeste.

Lo cierto es que las tierras áridas de La Mancha no atraían a nuevos pobladores cuya única y más importante actividad económica sería la ganadería por su adaptación tanto a la situación bélica del lugar como a la pertinaz sequía del mismo, que se había convertido en el rasgo peculiar y esencial de esta sociedad ${ }^{24}$.

Fue después de 1212 cuando se produjo una nueva fase repobladora que se prolongaría a lo largo de toda la Edad Media. Por una parte, el rey Alfonso VIII intentó mantener el control de la repoblación de La Mancha, y, un año después de su triunfo en las Navas de Tolosa, motivado por el abandono de la población musulmana, emprendió la repoblación

21 Linaje CONDE, A. "La difusión del Fuero de Sepúlveda en la Orden de Santiago. En torno a la creación del derecho municipal». Actas del $1 .^{\text {er }}$ Congreso de $H^{a}$ de Castilla La Mancha. Ciudad Real 1988, T. V, pág. 164.

22 W.AA., "La encomienda de Campo de Criptana a fines del siglo XV. "Descripción de bienes y análisis de rentas", Actas. T. VI, pág. 54.

23 A través del Fuero de Uclés se trataba de atraer a los pobladores pues: "todos los vecinos eran iguales ante la ley. Se eximió de montazgo al ganado de Uclés. Cualquier vecino, después de habitada un año, tenía derecho a vender su propiedad y marcharse»... Esto chocaba con otros fueros señoriales según los cuales el señor podía confinar la hacienda de los que se marchasen. Cfr. Lomax, D. W., op. cit. págs. 120-122.

${ }^{24}$ BISHKo, J. Ch., “El castellano hombre de llanura. La explotación ganadera en el área fronteriza de La Mancha y Extremadura durante la Edad Media», Homenaje a Vicens Vives. Barcelona 1965, T.I. págs. 201-218. 
de algunos lugares; tal fue el caso de Alcaraz y Chinchilla. Empresa que siguieron sus sucesores y cuyo ejemplo más próximo lo encontramos en la fundación de Ciudad Real por el rey Alfonso X en 1255, en el lugar de Pozuelo de don Gil, donde vinieron a asentarse vecinos de Alarcos ${ }^{25}$. $Y$ por otra parte, las Órdenes Militares fundaron también diversos núcleos de población. La Orden de Calatrava en Malagón y Miguelturra, entregada por el maestre a Martín Rodríguez; la Orden de Santiago en Quintanar y el Campo de Montiel, etc... Para su repoblación los caballeros de Santiago contaron con la colaboración de miembros de la nobleza como fue el caso del Conde Alvar Nuñez de Lara, que recibió de la orden en 1217, el lugar de Alhambra, como posesión vitalicia, o de Ordoño Álvarez, quien intervino en la repoblación de Villanueva de la Fuente. Durante la primera mitad del siglo xill, la Orden de Santiago había dado un fuerte impulso al proceso repoblador, como lo pone de manifiesto la construcción de 18 iglesias cuyos feligreses pagaban el diezmo correspondiente ${ }^{26}$. El maestre ordenó un considerable número de pueblos en La Mancha: en 1275, El Toboso; hacia la misma fecha, Villacañas; en 1276, la Puebla de Almoradiel, la cual obtendría el villazgo en $1341^{27}$.

A pesar de todos los esfuerzos realizados en la tarea repobladora y de la continua concesión por una parte de la Corona de algunas exenciones y privilegios ${ }^{28}$, no se consiguieron los frutos que se deseaban, y la repoblación seguía su curso lentamente. Hay que tener en cuenta, como destaca el profesor José Luis Martín, que las Órdenes Militares se reservaron para sí diversos privilegios señoriales: tiendas, hornos, carnicería, el cobro del portazgo, etc... como se recoge en el fuero dado en 1243 a Segura, que debió incidir, sin duda, en que la población se mostrase más reacia a poblar estos lugares manchegos frente a las tierras recién recuperadas del Valle del Gualdalquivir ${ }^{29}$.

25 Son de interés sobre este aspecto los siguientes trabajos. VILLEGAS DíAz, L. R., Ciudad Real en la Edad Media, La ciudad y sus hombres. (1255-1500). Ciudad Real 1981. SantIago Yustres, M., "Genésis y desarrollo del alfoz de Ciudad Real (1255-1347)", Actas del jer Congreso de Castilla-La Mancha. Ciudad Real 1988, T.V, págs. 173-185. Y la fundación de Ciudad Real y la Carta-Puebla. Excmo. Ayuntamiento de Ciudad Real, 1971.

${ }_{26}$ Lomax D. W., op. cit., págs 122-123. En 1243 se firma un acuerdo entre la Orden y el arzobispo don Rodrigo de Toledo, sobre los diezmos y derechos episcopales en las Iglesias del Campo de Montiel.

27 GonzÁlez, J., op. cit., pág. 368.

${ }^{28}$ El rey Alfonso X concedió en 1252 una feria a Montiel a beneficio de la Orden de Santiago. Cfr. González, J., op. cit., pág. 358. En 1261, el maestre excusó de pecho durante un año a todos los que se casaran por 1. ${ }^{a}$ vez en Montiel, Cfr. Lomax, D. W., op. cit., pág. 124.

${ }_{29}$ Martín, J. L., La Península lbérica en la Edad Media. Barcelona 1978, págs. 374-375 y Lomax, op. cit., págs. 123-124. 
El proceso continuó a lo largo del siglo xIV durante el gobierno de Alfonso XI y sus inmediatos sucesores aunque, ahora, con un marcado predominio señorial ${ }^{30}$. Don Juan Manuel, señor de Villena, Almansa y Chinchilla, concedió en 1319 a los pobladores de La Roda, la carta-puebla correspondiente con execión de pechos. Más tarde, en 1375, el Marqués de Villena otorgaba al lugar de Albacete con el villazgo los fueros de Chinchilla.

La Orden de Santiago prosiguió también con esta empresa poblacional, y hacia 1315 el maestre de la Orden fundó Corral de Almaguer y Sta. M de Torroba. Ese mismo año el rey Alfonso XI concedía al maestre un privilegio de exención de pechos para sus lugares de Quintanar y Valfermoso. Más hacia el sur se hizo otra puebla, la de Pedro Muñoz (1324), donde se levantaba un castillo que el maestre entregó al concejo del mismo pueblo ${ }^{31}$.

A mediado del siglo xIv se establece una importante institución jurídica con fines fiscales, son los comunes, es decir, comunidades de pueblos de la misma jurisdicción creados para mantener una mejor coordinación en el cobro de las rentas, lo que nos habla del grado de evolución en el proceso repoblador de esta zona. Lo más importante por lo que a nosotros atañe son: el común de Uclés, territorio de la Orden de Santiago que abarcaría desde el Tajo hasta el Cigüela. El común de La Mancha, creado en 1353, por el infante don Fadrique a fin de corresponder a las demandas de una serie de pueblos que exigían un reparto más equitativo de los impuestos ${ }^{32}$, abarca desde el Cigüela hasta el Guadina. El común de Montiel que comprendía desde el Guadiana al Guadalmena; y los comunes de los Campos de Calatrava y San Juan ${ }^{33}$.

El Campo de Montiel se transformó considerablemente en el siglo xv. En 1440 la Orden de Santiago decidió aumentar su población concediendo a los pobladores facultad para roturar tierras y exención tributaria durante diez años.

\footnotetext{
30 Villamayor de Santiago, carta - puebla en 1321 y villazgo en 1328; Villanueva de Alcardete, hacia 1328; Villatobas, Almenara, 1337; Villaescusa de Haro, carta de villazgo con fuero de Cuenca en 1349); Belmonte, 1366, villazgo en 1371; Puebla de Almenara, 1370, etc...

31 A finales del siglo xv éste y otros lugares del Campo de Criptana: Villajos, Tirez, Palomares, San Martín y Posadas. Cfr. Porras, P., Los señorios de la Orden de Santiago en la provincia de Castilla durante el sigloxv. Madrid, Universidad Complutense, 1982, págs. 476478.

32 Martín de NiCOLÁS J., «La Mancha santiaguista según los Libros de Visita (1480-1511), A.E.M., 11. Barcelona 1981, págs. 469-491.

33 Corchado Soriano, M., "La Mancha en el siglo Xvı...», op. cit., pág. 153.
} 
Durante el gobierno de los Reyes Católicos surge un nuevo impulso repoblador favorecido por la recuperación demográfica y la revalorización de los productos agrícolas, debido probablemente a inmigraciones de la región andaluza y a factores de crecimiento natural.

El afán repoblador siguió durante esta centuria. Y para ello los maestres de las Órdenes militares van a proseguir la atracción de inmigrantes mediante la concesión de fueros en condiciones ventajosas ${ }^{34}$; pues a pesar de que se fundaron nueva localidades a fines del siglo XV: los Cadosos (1475), Hontarejo, fundada en 1475 por los hermanos Martín Aparicio y Pero Sánchez; Saceruela, fundada en tiempos del gran maestre de Calatrava don Pedro Girón, quien tres años antes había fundado también la Puebla de Don Rodrigo cerca de este lugar; Pozuelos de Calatrava en 1470 , que había sido antes aldea de Caracuel, etc ${ }^{35} \ldots$ hay constancia que el Campo de Calatrava, en concreto, seguía casi despoblado a fines de la Edad Media ${ }^{36}$.

Podemos afirmar que en vísperas del descubrimiento de América no había finalizado la tarea de repoblación y todavía en el siglo XVI se seguía esta tendencia, momento en el que se produjo una fuerte expansión señorial provocada por las desamortizaciones eclesiásticas ${ }^{37}$, representadas por la segregación de los maestrazgos y la subsiguiente venta a particulares de ciertas encomiendas de las Órdenes Militares. Durante el reinado de Carlos $V$ y de su hijo Felipe II se procedió a la secularización y desmembración de los maestrazgos y mesas maestrales ${ }^{38}$.

\section{GRUPOS SOCIALES}

Fijémonos ya en ver cual era la Organización social en La Mancha a fines del siglo XV que lógicamente va a ser una consecuencia del proceso

34 Solano, E., La orden de Calatrava en el sigloxv. Sevilla 1975, pág. 376 . En 1417 el maestre da carta de población al lugar de Almadén que se encontraba despoblado, y para favorecer el aumento de sus habitantes, le concede una casi total exención de pechos, salvo el diezmo de las cosechas. Corchado Soriano, M., La orden de Calatrava y su campo. Ciudad Real 1984, pág. 83.

35 Salomón, N., La vida rural castellana en tiempos de Felipe /I. Barcelona 1982, págs. 3536.

36 Cfr. López-Salazar Pérez, J., Estructuras agrarias y sociedad rural en La Mancha (siglos XVI-XVII). Ciudad Real 1986, pág. 77.

37 Moxó, S. de, «Las desamortizaciones eclesiásticas en el siglo XV|», en AHDE, 1961, págs. 327-361.

38 En 1487 los Reyes Católicos incorporaron a la Corona las Órdenes Militares. Más tarde el Papa Adriano VI, en 4-5-1523, concedió una bula para tal fin, que fue confirmada por Paulo III (17-VIII-1536) y por Paulo IV, en 1-XII-1555. 
de repoblación que hemos señalado, vinculado a su vez a la guerra civil peninsular y el consiguiente crecimiento del poder estatal.

El proceso repoblador determinó la paulatina constitución de una sociedad diferenciada entre aquellos que poblaban las áreas rurales y aquel otro grupo, menos numeroso, que vivían en las áreas urbanas que a lo largo de los siglos bajomedievales se fueron constituyendo, aunque podemos afirmar que con anterioridad al siglo XVI no existieron ciudades de importancia en las que aparezcan diferenciados los grupos sociales, ni tampoco podemos hablar de que haya una población urbana notable. Ello fue debido al predominio de las actividades agrarias, y de una manera especial, al desarrollo de la ganadería que incidió en la ausencia de ciudades grandes.

Por tanto en La Mancha nos encontramos a grandes rasgos con una población que en su mayor parte habitará en las zonas rurales ${ }^{39}$, y otro pequeños grupo que se localiza en núcleos rurales grandes, que no podemos denominar ciudades propiamente tales, en los que se concentraban diversas actividades artesanales y mercantiles que le infundian un carácter económico diferente al del campo.

Durante el gobierno de los Reyes Católicos no se produjo desde el punto de vista social una ruptura con el pasado ni tampoco se produjeron modificaciones importantes, sino que, por términos generales, se mantuvo el "ordenamiento» social; aunque bien es verdad que los monarcas trataron de poner orden después del caos social imperante en el gobierno de Enrique IV y sus antecesores en la Casa de Trastámara y van a llevar a cabo una «regularización» de las diferentes fuerzas sociales, tratando de imponer una paz social, de inspiración marcadamente estamental ${ }^{40}$, donde cada estamento tiene una función específica que cumplir.

La concepción tripartita de la sociedad: defensores, oradores y labradores la encontramos reflejada en la mayoría de los escritos de la época: en el Libro de Los Estados de don Juan Manuel; en el Libro del Buen Amor del Arcipreste de Hita; en el Victorial de Gutierre Díez de Games, etc... en este último se resalta el carácter divino de tal división tripartita de la sociedad por lo que cambiar los designios divinos sería ir contra natura. Quizá un ejemplo de esta asunción lo tenemos en el Lazarillo de Tormes, Lázaro se lamenta y critica a la sociedad en que vive pero sin

39 IZQUiERdo, R., Castilla-La Mancha. Historia, arte y etnologia. Junta de Comunidades Castilla-La Mancha, 1985, pág. 70.

40 Cfr. Gutiérrez Nieto, J. I., «La estructura castizo-estamental de la sociedad castellana del siglo XV|», Hispania XXXIII, 1973, págs. 529-531. 
embargo no tenía empeño de «revolución social» sino que sabe cuál es su sitio y espera simplemente a pasar la vida.

El paso de un estamento a otro no era fácil, cada grupo se cerraba frente a los que poseían diferentes obligaciones. Este proceso fue común para toda Europa siendo el período que se extiende de 1250 a 1600 el de más rigurosa jerarquización de las capas sociales, según manifestaba $\mathrm{M}$. Bloch ${ }^{41}$. El medioevo no podía concebir una sociedad que no estuviese estructurada en grupos desiguales, de ahí que la sabiduría popular lo conservase y transmitiese a través incluso de algún refrán ${ }^{42}$.

En la cúspide de esa sociedad estamental se encuentra la Nobleza. Es de todos conocido el papel que a lo largo de la Edad Media desempeñó este grupo, y de una manera especial durante la guerra civil castellana al tomar partido por uno $u$ otro bando, acudiendo en su apoyo mediante el servicio de armas. Los reyes necesitaban a la nobleza y buena prueba de ello son las numerosas mercedes y privilegios que les concedieron de un modo especial después del importante suceso que tuvo lugar dentro del área que hoy nos ocupa, como fue la victoria de Enrique II en Montiel en 1369, y la consiguiente subida al trono de la Casa de Trastámara. Tal fue el poder alcanzado por la nobleza que los Reyes Católicos se vieron obligados a frenar este ascenso por cuanto peligraba su poder.

Pero centrémonos en La Mancha donde, por sus propias condiciones antes apuntadas, vamos a encontrar unas características específicas al referirnos a las jerarquías sociales que en ella encontramos.

Dentro del grupo nobiliario ocupan un papel primordial los Maestres de las Órdenes Militares especialmente de Calatrava y Santiago, eran la suprema autoridad de sus respectivas órdenes y formaban parte del Consejo Real de Castilla ${ }^{43}$; el maestre tenía bajo su potestad un señorío o maestrazgo y estaba investido de jurisdicción y mando militar sobre todos los caballeros y huestes de la Orden ${ }^{44}$.

${ }^{41}$ Cfr. BLoch, M., La societé féodale Il. Les clases et le gouvernement des hommes. París 1960, pág. 66.

${ }_{42}$ Véase la obra de Stefano, Luciana de, La sociedad estamental de la Baja Edad Media española a la luz de la literatura de la época. Universidad de Venezuela, págs. 29-54. En la página 54 recoge un refrán alemán que dice así: Dios ha creado tres órdenes en el mundo: regentes - nobles-- sacerdotes y el pueblo; hiciera cada uno su deber, así estaría el mundo bien organizado.

43 Según las Cortes de Toledo de 1480 se dio una ordenanza por la que los maestres junto con los magnates y grandes del reino, arzobispos y obispos podían asistir a las deliberaciones de Consejo pero sin voto.

${ }_{44}$ Desde el siglo XII las $O$. Militares se convirtieron en titulares de numerosos señoríos, pues 
Dentro de este grupo nobiliario se engloban también otras personas que por determinadas condiciones han entrado a formar parte del mismo, como sería el caso de los Comendadores de las Órdenes Militares ${ }^{45}$.

Junto a los nobles miembros de las Órdenes Militares que constituían el grueso de este grupo aristocrático, encontramos también asentados en La Mancha a algunos linajes nobiliarios, aunque en menor número, ya que como hemos podido apreciar de lo hasta aquí expuesto, la ocupación por las Órdenes militares de extensas áreas manchegas puso freno y fue un obstáculo para el establecimiento de cualquier otro poder. Incluso la propia realeza va a mantener este recelo respecto a la creación de señoríos laicos en la zona ganadera situada al sur del reino de Toledo, y ésta va a ser una de las características que marca la diferencia entre La Mancha y el Reino de Toledo, pues en éste último, el proceso señorializador alcanzó altas cotas en el siglo XV ${ }^{46}$.

Uno de estos linajes nobiliarios que no podemos dejar de mencionar y que al mismo tiempo estuvo vinculado a las Órdenes Militares, es el linaje de los Pacheco, Marqueses de Villena. El señorío que poseían se extiende por el noroeste de la Mancha. Limita con los centros de la Orden de Santiago: Uclés y Quintanar por el norte; con el reino de Aragón por el este; y con diversos lugares de las Órdenes Militares: Montiel e Infantes, de la Orden de Santiago; Alcázar de San Juan y Almagro, de la Orden de Calatrava; y con Alcaraz, villa de realengo y con el reino de Granada por el oeste, siendo las villas más importantes de este señorío, Villena, cabeza del mismo, Belmonte, Alarcón, Chinchilla, Almansa, Utiel y Villarrobledo, entre otros.

Fue el rey Enrique Il quien concedió a don Alfonso de Aragón el título de Marqués de Villena como pago a la ayuda que le prestara en la lucha que mantuvo con su hermanastro Pedro l. La época más floreciente del marquesado fue desde 1366 a $1395^{47}$. Durante la $1 .^{a}$ mitad del siglo XV el señorío fue incorporado a la Corona ${ }^{48}$, siendo recuperado el título de

los Reyes en compensación a los servicios prestados les concedieron en pleno señorío extensos territorios. En los señorios entregados por Alfonso VIII se otorga la jurisdicción. En el privilegio que se concede a Uclés encontramos la fórmula «omnibus directuris". Cfr. Moxó, S. de, "En torno a una problemática para el estudio del régimen señorial», Hispania, XXIV, 1964, págs. 6 13.

45 Cfr. Ladero Quesada, M. A., Los Reyes Católicos y la unidad de España. Valencia 1989, pág. 45 .

46 Cfr. Moxó, S. de, Los antiguos señoríos de Toledo. Toledo 1973.

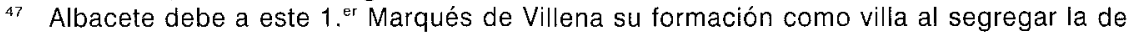
Chinchilla (1375). Véase FriAs, I., Juan Pacheco. Marqués de Villena 1419-1479. UNED, Tesis Doctoral, 1990.

${ }_{48}$ Pretel Marin, A., "En torno a la incorporación del Marquesado de Villena a la Corona castellana en 1395", Al-Basit, 6, 1979, págs. 163-176 
Marqués por Juan Pacheco en 1445, durante el reinado de Juan II en premio a su colaboración en la batalla de Olmedo. Pero el hecho de que su hijo Diego López Pacheco mostrase su apoyo a los partidarios de Juana la Beltraneja motivó su destitución del señorío, villas y lugares por los Reyes Católicos quienes lo incorporaron a la Corona. A partir de entonces todo el marquesado pasó a denominarse «Gobierno del Marquesado de Villena" con capital en Chinchilla, quedando el título de Marqués de manera honorífica ${ }^{49}$.

Respecto a la media y baja nobleza, pocos son los datos de que disponemos acerca de estos grupos para la Mancha. Únicamente tenemos algunos testimonios sobre un grupo de hidalgos y caballeros que vivían en Villa Real, aunque no se establece ninguna distinción jurídica entre ellos, se sabe formaban la oligarquía urbana. Hay asimismo noticias sobre los Hidalgos que residían en Almagro, donde frecuentemente, según la documentación existente, alcanzaron el control del gobierno y de la administración, al tiempo que estaban exentos de cargas fiscales, lo cual no estaba de acuerdo con los intereses de la Orden de Calatrava ${ }^{50}$.

Documentos referentes a la villa de Alcaraz, nos dan noticias de ciertos caballeros cuantiosos, capaces de mantener armas, los cuales apoyándose en familias hidalgas fueron adquiriendo poder hasta llegar a equipararse con ellos. Otros grupos, procedentes de la caballería villana, fueron asimismo acumulando riquezas debido a su actitud agropecuaria lo que les va a permitir ascender dentro de la jerarquía social. No obstante los Reyes Católicos trataron de fijar los requisitos necesarios para el reconocimiento de Hidalguía en las Leyes de Córdoba de 1492.

En suma, podemos decir que tanto los hidalgos, pequeña nobleza, a veces empobrecida, pero que tratará siempre de mantener su «status». El hidalgo se resiste a descender, y fingía tener lo que no poseía. (Recordemos por ejemplo como el hidalgo pobre del Lazarillo de Tormes se dirige a Lázaro preguntándole si busca amo). Como los caballeros, oligarquía nobiliaria asentada en las ciudades, fueron numéricamente poco importantes en La Mancha como consecuencia del dominio señorial de las Órdenes Militares y del escaso desarrollo urbano.

49 En las Cortes de Toledo de 1480 los procuradores del reino pidieron que se anulasen todos los juros y enajenaciones concedidos por Enrique IV. Pero los Reyes Católicos mandaron hacer una rigurosa revisión para ver si entre ellos había alguno justo. Después de hacerla, los RR.CC. dictaron un ordenamiento en el que, entre otros asuntos, se mandaba revocar lo concedidó al Marqués de Villena. Matilla Tascón, A., Declaratoria de los Reyes Católicos sobre la reducción de juros y otras mercedes. Madrid 1966, pág. 66.

so Solano, E., op. cit., págs. 369-370. 
La mayor parte de la población la integraba el campesinado, «los que labran la tierra et facen en ella aquellas cosas porque los homes han de vevir et de mantenerse» (Part.Il, T. XXI). Grupo que aparece íntimamente ligado a la nobleza en el régimen señoral; sin embargo, a pesar de ser un grupo muy numeroso es poco conocido, las fuentes documentales como señalaba el profesor Julio Valdeón en el 1 er $^{\text {er }}$ Congreso de Castilla La-Mancha no ofrecen tantas noticias como para otros ámbitos territoriales de la Corona de Castilla, como para la Meseta norte o el valle del Guadalquivir ${ }^{51}$.

Aunque por campesino se engloba a todo aquel que labra la tierra, podemos hacer una diferenciación interna, distinguiendo al labrador del jornalero, por ejemplo. Los labradores eran los campesinos, más o menos acomodados y establecidos con carácter permanente. Sabemos por algunos fueros otorgados al campo de San Juan que las Pueblas se formaron, por término medio, con un 85 por 100 de labradores quiñoneros y un 15 por 100 de menestrales los cuales recibían solar para una casa y una aranzada para viña o huerta, mientras que los labradores recibían además 1 yugada de labor equivalente a 30 Has $^{52}$. Muchos de estos labradores, declara E. Solano, compaginaban sus tareas agrícolas con otros oficios como barberos, herradores, horneros o carpinteros, entre otros $^{53}$.

Las órdenes militares tratan de favorecer el asentamiento de inmigrantes labradores por cuanto no sólo consolidaban la posesión de su campo sino que además aumentaban sus ingresos a través de los diezmos de las cosechas.

Otro grupo dentro del campesinado lo formaban los jornaleros y entre ellos cabe hacer una distinción entre los que trabajaban la tierra durante un año y los que realizaban tareas agrícolas durante un espacio de tiempo breve. Una de las denominaciones específicas de la Mancha, según se contempla en los ordenamientos de las Cortes bajomedievales, sería la de los mesegueros encargados de guardar las mieses ${ }^{54}$.

51 Publicado por la Junta de Castilla-La Mancha, T. VI, pág. 6.

52 Alfonso VIII ordenó al Concejo de Calatrava que la Orden tuviera en cada castillo 40 yugadas (1.200 Has.) distribuyendo lo demás en quiñones a los pobladores. El quiñón permitía la explotación familiar de una yunta, es decir, lo que dominaba una pareja de bueyes en labor de año y vez, (30 Has). Corchado Soriano, M., La orden de Calatrava y su campo, op. cit., pág. 116.

53 Solano, E., op. cit., pág. 370.

54 VALDEÓN, J., op. cit, pág. 7 y nota 12. 
No podemos olvidar dentro del campesinado a los pastores, ya que el pastor constituye junto al caballero un elemento singular y característico dentro de La Mancha. Así lo puso de relieve Salvador de Moxó cuando al hablar de este lugar lo denominaba «Tierra del pastor y del caballero» ${ }^{55}$.

Además debemos tener presente que la ganadería ocupaba un lugar de suma importancia en la economía manchega, y la vamos a encontrar en todo el espacio, a uno y otro lado del Guadiana, tanto en la comarca de los pastos de Santiago como en la comarca de los pastos de Calatrava ${ }^{56}$. Recordemos además, que gran parte del Campo de Calatrava era preferentemente tierra de pastos que aprovechaban de invernadero los ganados trashumantes, por lo que por este motivo se constituyeron los llamados comunes, a los cuales nos hemos referido anteriormente. A menudo se produjeron algunos enfrentamientos entre los ganaderos de las Órdenes y los ganaderos trashumantes ${ }^{57}$.

Aunque la actividad agropecuaria fue la predominante para estos campesinos ${ }^{58}$ también se ocuparon de otros trabajos como de la apicultura, explotación de las colmenas y su aprovechamiento, así como del trabajo para la obtención del carbón vegetal, en sus diferentes clases.

Las condiciones de vida del campesinado, aún cambiantes en relación con su personal dependencia señorial, empeoraron a fines de la Edad Media. Los contratos de arrendamiento solían hacerse a corto plazo, con lo que periódicamente se subía la renta. El campesino, subordinado jurídicamente a su señor, veía cambiar su forma de vida en relación con las estaciones del año y sus respectivas necesidades agrícolas, alternándose tiempos de gran actividad con otros de profunda calma. Simultáneamente el campesino se ocupaba de su huerto y de algún animal doméstico. A pesar de todo, Nöel Salomon en su conocida obra sobre la vida rural castellana, pone de relieve que la situación del campesino de lo que él denomina Castilla la Nueva, “atravesó el umbral de los tiempos modernos con la cabeza alta como un hombre libre y orgulloso de que sus antepasados no hubieran sido víctimas de la verdadera servidumbre

55 Moxó, S. de, Repoblación, op. cit, 241.

56 Tengamos también presente que las Órdenes Militares obtuvieron ingresos importante por el arrendamiento de dehesas y tierras de pastos. Sabenos que en 1470 formaban parte del ganado del convento 480 cabezas, pero no se sabe su composición. Cfr. Corchado Soriano, M., op. cit., págs. 115-6.

${ }_{57}$ Véase sobre este aspecto López-Salazar PÉrez, J., Mesta, pastos y conflictos en el Campo de Calatrava (siglo xvl). Madrid 1987, págs. 37-44.

${ }_{58}$ Los Fueros de población resaltan la obligación de la puesta de Viña, con ello se pretendía ganar tierras y fijar pobladores con un cultivo arraigado y con un ciclo más largo que los cereales. CORCHADO, M., op. cit. págs. 115-117. 
absoluta: y hace hincapié en resaltar la situación jurídica y política privilegiada de que disfrutaba el campesino castellano en comparación con los campesinos de Aragón, Cataluña o del mediodía francés por el mismo tiempo ${ }^{59}$.

A pesar de esta situación el campesino contemplaba cómo sus condiciones de vida experimentaban una degradación, de ahí que se produjesen algunos levantamientos de protesta como el que tuvo lugar en Yeste (Albacete), perteneciente a la Orden de Santiago, donde se levantaron en 1479 los pequeños y medianos propietarios de tierras agobiados por la presión fiscal que sufrían. Las desigualdades sociales se agudizaban a finales del siglo xv, produciéndose un aumento de la población campesina asalariada. Las tierras para nueva roturación se entregaban a Hidalgos y Caballeros de cuantía, no quedando más opción para el campesino que convertirse en censatario o arrendador de las mismas. A ello habría que añadir la pertinaz sequía que sufrieron a finales del siglo $\mathrm{xv}$, siendo el año de 1503 el más crítico ${ }^{60}$.

No podemos dejar de mencionar en el conjunto de la historia social, a otros grupos de población que residían en el área manchega y que se vienen englobando dentro de la población marginal: pobres vagabundos, mendigos, pícaros, etc... de los que únicamente tenemos referencias literarias para esta zona aunque recientemente se han publicado algunas obras de conjunto sobre estos grupos ${ }^{61}$; y de otros grupos minoritarios: judíos y musulmanes cuya convivencia entre ellos y junto a los cristianos se ha mantenido a gala, hasta que el 31 de marzo de hace ahora 500 años, se hizo público el decreto de expulsión de los judíos, poniendo fin con ello a la convivencia de las Tres Culturas. iQué lejos de la realidad estaban aquellas palabras recogidas en el privilegio dado por Enrique IV a Juan Pacheco en el que se le hacía concesión del señorío de la Puebla de Montalbán en Toledo y que dice así: «...con todos sus criados, así cristianos como judios y moros que ahora viven y moran y hubieren y vivieren y moraren de aquí en adelante» ${ }^{62}$

Hay constancia de aljamas judías en La Mancha, cuyos pobladores se dedicaron preferentemente a las actividades mercantiles. Sabemos que la

59 Salomón, N., op. cit., pág. 185.

6o Los ideólogos santiaguistas traban de mantener y demostrar el clima de paz y armonía que existía en el interior de la Orden... «El maestre e la orden e el pueblo que valen poco la una sin la otra..." Cfr. Rodriguez LLOPIS, M., "Protesta popular y conflictos de clase. Los levantamientos campesinos de Yeste (Albacete) en el reinado de Isabel l», Acta, op. cit., t. VI, págs. 141-146.

61 López Alonso, C., La pobreza en la España Medieval. Madrid 1986.

62 Moxó, S. de, “En torno a...», op. cit., pág. 27. 
concesión hecha por el rey Alfonso $\mathrm{X}$ a beneficio de la Orden de Santiago de celebración de una feria en Montiel, fue un foco de atracción para los judíos. De la misma manera que lo fueron las que se celebraban en Almagro y Almodóvar en el Campo de Calatrava. Hay pruebas también de que los judíos acudieron a poblar Villa Real después de su fundación, prefiriendo estar bajo la autoridad directa del rey de Castilla, antes que a las órdenes de los maestres. No obstante hubo un grupo importante en Almagro, Montiel, Manzanares, Alcázar de San Juan, Daimiel y Almadén donde trabajaban en servicio de los grandes señores, maestres de las Órdenes Militares.

Otra minoría de población era la mudéjar. Aunque la documentación no se muestra muy explícita al hablarnos de su asentamiento, parece ser que hubo un grupo de cierta importancia en Almagro, Villarrubia, Aldea del Rey y Daimiel, en tierras de la Orden de Calatrava; y en Ocaña, Montiel y Uclés, dominios de la Orden de Santiago ${ }^{63}$. Y dentro de este grupo hay que hacer una distinción entre los mudéjares libres, que trabajaban en el campo en régimen de arrendamiento en su mayor parte, o desempeñaban otros oficios como zapateros, herradores, pastores o criados; de aquellos otros mudéjares que eran esclavos y de los que la Orden de Calatrava no quería prescindir a pesar de los acordado en las Capitulaciones de Granada, por razones de índole económica ${ }^{64}$.

Ya para concluir me voy a permitir hacer una breve reflexión sobre el año 1492, cuyo $V$ centenario conmemoramos. Año en que tres acontecimientos de suma importancia, sin entrar en sus respectivas valoraciones, tuvieron lugar bien dentro de la Península o fuera de ella pero actuando ésta como protagonista: La toma de Granada; La expulsión de los judíos y El descubrimiento de América. ¿Supusieron todos ellos una ruptura con los tiempos anteriores?, ¿Llegaron a su culminación los elementos que marcaban el tránsito de una etapa histórica a otra según tradicionalmente venimos admitiendo al hablar de la periodización en la historia?

Creo para el caso de los reinos hispánicos que estos sucesos dejaron una profunda impronta que nos separaba en aquel momento del resto de Europa: de la Francia de Carlos VII, donde las guerras con Italia a partir de 1494 no significaron gran cosa; y de la Inglaterra donde la subida al

63 Menchero MÁrquez, P., «Presencia musulmana en la villa de Bolaños siglos XV y XVl», Comunicación presentada en el / Simposio La Mancha y América hace quinientos años (1492. 1700 ).

64 Ladero Quesada, M. A., Los mudéjares de Castilla y otros estudios de H. ${ }^{a}$ Medieval andaluza. Granada 1989, págs. 91-100. 
trono de Enrique VII y su boda con Isabel de York, puso fin a la guerra de las Dos Rosas.

Sin embargo algo teníamos en común con estos reinos, al igual que la casa de Avís de Portugal, y era, sin duda alguna, el robustecimiento de sus respectivas monarquías, que marcaban el inicio de las nuevas monarquías modernas. 